\title{
Examining the Transition To Engineering: A Multi-Case Study of Six Diverse Summer Bridge Program Participants
}

\section{Walter C. Lee, Virginia Tech}

Walter Lee is a PhD candidate in the Department of Engineering Education at Virginia Tech, where he also serves as a program assistant for the Center for the Enhancement of Engineering Diversity. His research interests include student retention, diversity, motivation, and first-year experiences in engineering. Mr. Lee received an NSF Graduate Research Fellowship in Spring 2012 focusing on how co-curricular support is used to impact the experiences of undergraduate engineering students, specifically those from underrepresented populations. He received his M.S. in Industrial \& Systems Engineering from Virginia Tech and his B.S. in Industrial Engineering from Clemson University.

\section{Ms. Christina Nocon Seimetz, Virginia Tech}

Christina Seimetz is a PhD student in the Department of Engineering Education at Virginia Tech. She also serves as program support staff for the Center for the Enhancement of Engineering Diversity where she is involved with recruitment, outreach, and retention programs specifically targeted towards females interested in engineering. Ms. Seimetz earned her B.S. in Mechanical Engineering and her M.S. in Biomedical Engineering from Virginia Tech.

\section{Dr. Catherine T. Amelink, Virginia Tech}

Dr. Catherine Amelink is Director of Graduate Programs and Assessment, College of Engineering, Virginia Tech. 


\title{
Examining the Transition To Engineering: A Multi-Case Study of Six Diverse Summer Bridge Program Participants
}

\begin{abstract}
The first year of engineering is critical as students often find it difficult to make the transition from being high school seniors to college freshmen. In an attempt to mitigate this transition, many colleges offer summer bridge programs that aim to provide students with enriching experiences believed to facilitate the acquisition of the skills needed to be successful in college. However, students can benefit from and experience a program differently even if they participate in the same activities. Our research study contributes to understanding how students benefit from a five-week summer bridge program by examining the experiences of six students with varying backgrounds. While the program initially targeted only engineering students from underrepresented ethnic minority populations, it has since expanded to be open to all engineering students as well as those who are accepted into the university but not directly into engineering. The purpose of this multicase study is to highlight individual experiences: particularly the impact that participation in a summer bridge program can have on academic motivation and the lessons students learn as they transition towards engineering. While each student did report an improved understanding of how much effort is required to earn an engineering degree, lessons pertinent to the personal transition of each student were also revealed. The findings presented in this paper will assist engineering colleges with helping students with the college transition.
\end{abstract}

\section{Introduction}

Interventions targeting first-year students are common efforts engaged in by engineering colleges in order to improve undergraduate retention. Since students often find it difficult to make the transition from being high school seniors to college freshmen, the first year of engineering is critical. In an attempt to facilitate this transition and motivate students as they begin their academic careers, many colleges provide summer bridge programs ${ }^{[1]}$. Summer bridge programs aim to provide incoming students with early contact and enriching experiences believed to facilitate the acquisition of the skills needed to be successful in college. However, students can have varying experiences even if they participate in the same activities. Since studies focusing on summer bridge programs are typically quantitative and primarily focus on academic performance and retention ${ }^{[2,3]}$, we know little about how these experiences vary and the many different ways students may benefit from such programs.

While academic gains are important, it is imperative that we also increase our understanding of how students are impacted by participation in summer bridge programs, particularly regarding their motivation towards earning an engineering degree. Since summer bridge programs are not designed identically (i.e., the structure and duration of these programs vary across universities), understanding how students experience these interventions at a micro-level is important as it will assist practitioners with making decisions that increase the chances of students being impacted in the intended manner. This study contributes to our understanding of how students benefit from summer bridge programs by examining the experiences of six students with varying backgrounds who participated in the Student Transition Engineering Program (STEP), a five-week summer bridge program held at Virginia Tech, during Summer 2013. The purpose of this multicase study ${ }^{[4,5]}$, where each student serves as an individual case, is to highlight the individual experiences of 
students who participated in STEP. The study will also seek to identify lessons learned through the program and the impact participating in STEP had on each student's academic motivation.

Grounded in the Music Model of Academic Motivation ${ }^{[6,7]}$, our overarching research question is:

\section{What impact can participating in a five-week summer bridge program have on the academic motivation of a student as he or she transitions towards earning an undergraduate degree in engineering?}

We begin with a brief overview of the MUSIC Model of Academic Motivation. Next, we discuss STEP and what this entails for participating students. Third, the methods used to collect and analyze the data are discussed. Following, we will present narratives that individually summarize the experiences of each student. Lastly, we will discuss how participating in a summer bridge program can impact students with different backgrounds and different reasons for participation, and offer advice for practitioners who coordinate or direct similar programs.

\section{Theoretical Framework}

The MUSIC Model of Academic Motivation ${ }^{[6,7]}$ focuses on five primary motivation components: (1) empowerment, or students believing they have control over their academic experiences; (2) usefulness, or students understanding how the content they are learning is valuable; (3) success, or students believing they can perform well if they put forth the effort; (4) interest, or students finding what they're learning enjoyable and valuable; and (5) caring, or students feeling cared about academically and personally. Designed to be a comprehensive model of academic motivation, the original purpose of the MUSIC Model was to assist instructors with designing courses in a way that motivated students to engage in learning ${ }^{[6]}$. While the model was designed for and is typically used in more traditional classroom settings ${ }^{[8]}$, it has also been demonstrated to be applicable in other learning environments such as summer bridge programs ${ }^{[9]}$. That is to say, the model can also be used to assist practitioners with designing interventions that motivate students to engage in learning.

Lee and colleagues ${ }^{[9]}$ provide a foundation for our study; they hypothesized that retaining engineering students was related to academic motivation, and asserted that the components of the MUSIC Model would be evident in the design of interventions used by engineering colleges to support students. To test this hypothesis, the researchers operationalized the MUSIC constructs and investigated how interventions that have been proven successful in attracting and retaining student met each aspect of the model from the perspective of the administrators (i.e., coordinators and directors) who were responsible for designing and directing student interventions at a university. As a result of the study, it was determined that each MUSIC component was represented in almost every intervention, though emphasis varied. For example, the researchers discovered that success then empowerment and caring were most heavily emphasized in the summer bridge program they examined; this was not the case for interventions such as mentoring programs or living-learning communities ${ }^{[9]}$. Complementing the administrator perspective taken by Lee et al ${ }^{[9]}$, this study uses the model to investigate the student experience during a summer bridge program. 


\section{Program Description}

STEP was developed to ease the transition of students from underrepresented ethnic populations as they entered Virginia Tech, which is a large, public research university. Participation in STEP is voluntary (i.e., each student has to apply and pay a fee if selected) and the program lasts for five weeks, beginning on the last Sunday of June. While STEP initially targeted only underrepresented engineering students, it has since expanded and is open to all engineering students as well as those who are accepted into the university but not directly into engineering; this broad target population often results in a diverse group of participants with regards to gender, race, academic preparation, socio-economic status, and current major. Intended to provide students with a quasi-college experience, the stated purpose of the program is as follows: (1) to provide incoming students an opportunity to become familiar with the university community; (2) to provide academic enrichment in subjects historically difficult for first-year students; and (3) to provide incoming students with opportunities for personal and professional development.

During STEP, students participate in academic, professional development, and social activities. Academic activities consist of four courses (engineering, math, chemistry, and chemistry lab) and either a faculty member or graduate teaching assistant leads each course. In addition to attending class, students also attend seminars on Monday through Thursday evenings, on Friday afternoons, and, less frequently, on Saturday mornings. These professional development activities include seminars on research presented by engineering faculty from various departments at the university; seminars on campus resources presented by various campus services such as career services; seminars/workshops on topics such as teambuilding and resumes from sponsoring companies; or general meetings with the associate dean of academic affairs, who also serves as the director for the student support center that sponsors STEP. Additionally, students have ample opportunities to participate in social activities. Social activities, which are optional, include activities such as movie night or volleyball and are organized by the program assistant and four resident assistants, all of which are engineering students. An example of a class schedule can be found in Figure 1 below. 


\begin{tabular}{|c|c|c|c|c|c|}
\hline \multicolumn{6}{|c|}{ Group A Schedule } \\
\hline & Mondey & Tuesday & Wednesday & Thursday & Friday \\
\hline \begin{tabular}{|l|}
$7: 00 \mathrm{AM}$ \\
$7: 15 \mathrm{AM}$ \\
$7: 30 \mathrm{AM}$
\end{tabular} & Breaktast & Breakfast & Breokfast: & Breakfast & Breaktast \\
\hline $7: 45$ AM & & & & & \\
\hline 8:00 AM & \multirow{6}{*}{ Chem - Dr. Smith } & & \multirow{6}{*}{ Chem - Dr. Smith } & \multirow{6}{*}{ Chem - Dr. Smith } & \multirow{6}{*}{ Chem - Dr. Smith } \\
\hline $8: 15 \mathrm{AM}$ & & & & & \\
\hline 8:30 AM & & & & & \\
\hline $8.45 \mathrm{AM}$ & & & & & \\
\hline $9: \mathrm{CO} \mathrm{AM}$ & & & & & \\
\hline $9: 15$ AM & & & & & \\
\hline $9 ; 30 \mathrm{AM}$ & & & & & \\
\hline 9:45 AM & \multirow{3}{*}{ Math - Df Jahn } & & \multirow{3}{*}{ Math - Dr Jehn } & \multirow{3}{*}{ Math - Dr. John } & \multirow{3}{*}{ Wath - Dr, Jahn } \\
\hline $10: 00$ AM & & & & & \\
\hline $10: 15$ AM & & Chem Lab & & & \\
\hline 10:30 AM & \multirow[t]{3}{*}{ Roam 220} & Dr. Brown & \multirow[t]{3}{*}{ Reem 220} & \multirow[t]{3}{*}{ Rocem 220} & \multirow[t]{3}{*}{ Roam 220} \\
\hline $10: 45$ AM & & & & & \\
\hline $11: 00 \mathrm{AM}$ & & Room 330 & & & \\
\hline \multicolumn{6}{|l|}{$11: 15 \mathrm{AM}$} \\
\hline \multicolumn{6}{|l|}{$11: 30 \mathrm{AM}$} \\
\hline \multicolumn{6}{|l|}{$11: 45 \mathrm{AM}$} \\
\hline \multicolumn{6}{|l|}{$12: 00 \mathrm{PM}$} \\
\hline $12: 15 \mathrm{PM}$ & & & & & \\
\hline $12: 30 \mathrm{PM}$ & & & & & \\
\hline $12.45 \mathrm{PM}$ & Lunch & unch & Lunch & Luneth & Lanch \\
\hline $1: 00 \mathrm{PM}$ & & & & & \\
\hline $1: 15 \mathrm{PM}$ & & & & & \\
\hline $1: 30 \mathrm{PM}$ & & & & & \\
\hline $1.45 \mathrm{PM}$ & & & & & \\
\hline $2: 00 \mathrm{PM}$ & & & & & \\
\hline $2: 15 \mathrm{PM}$ & & & & & Serninar 1 \\
\hline $2: 30 \mathrm{PM}$ & & & & & \\
\hline $2: 45 \mathrm{PM}$ & Engr = Dr. Lee & Advising & Engr = Dr. Lee & Advising & \\
\hline 3:00 PM & & & & & \\
\hline $3: 15 \mathrm{PM}$ & Room 110 & Teo & Roam 110 & TBD & Seminar 2 \\
\hline $3: 30 \mathrm{PM}$ & & & & & \\
\hline $3: 45 \mathrm{PM}$ & & & & & \\
\hline $4: 00 \mathrm{PM}$ & & & & & \\
\hline $4: 15$ PM & & & & & \\
\hline $4: 30 \mathrm{PM}$ & & & & & \\
\hline $4: 45 \mathrm{PM}$ & & & & & \\
\hline 5:CO PM & & & & & \\
\hline 5:15 PM & & & & & \\
\hline 5:30 PM & & & & & \\
\hline $5: 45$ PM & Drner & Dinner & Dinner & Dinner & Drner \\
\hline 6:00 PM & & & & & \\
\hline $6: 15$ PM & & & & & \\
\hline $6: 30 \mathrm{PM}$ & & & & & \\
\hline $6: 45 \mathrm{PM}$ & & & & & \\
\hline 7:00 PM & & & & & \\
\hline
\end{tabular}

Figure 1: Class Schedule 
STEP typically involved between 70-95 students. At the beginning of the program, the group is divided into three sections (Groups A, B, and C) and each student is assigned a corresponding schedule. Each schedule includes the same courses, though the time and instructors may vary; Figure 1 represents a possible class schedule for one of the sections. Lastly, students are required to attend two seminars every Friday afternoon: the first, Seminar 1, being a large general seminar on a topic such as time management or undergraduate research; and the second, Seminar 2, being a smaller research seminar with an engineering professor (the students could select from 1 of 3-4 options for Seminar 2 each week on first-come-first-serve basis).

Students are also provided an activity schedule that lists each evening and weekend activity that the students are required to attend during STEP. The activity schedule includes a date, time, and location for each activity as well as any additionally information students would need to prepare such as a dress restriction.

Since social activities are optional and planned by the STEP staff as the program progresses, students are not provided with a schedule of these activities in advance: they are notified of events haphazardly. Students would stick to the provided schedule and participate in social activities for the duration of the five-weeks.

\section{Methods}

The impact STEP has on participating students was examined using a qualitative multicase study of participants from the 2013 cohort. The demographics for the cohort are provided in Table 1 below.

Table 1: STEP Demographics (2013 Cohort)

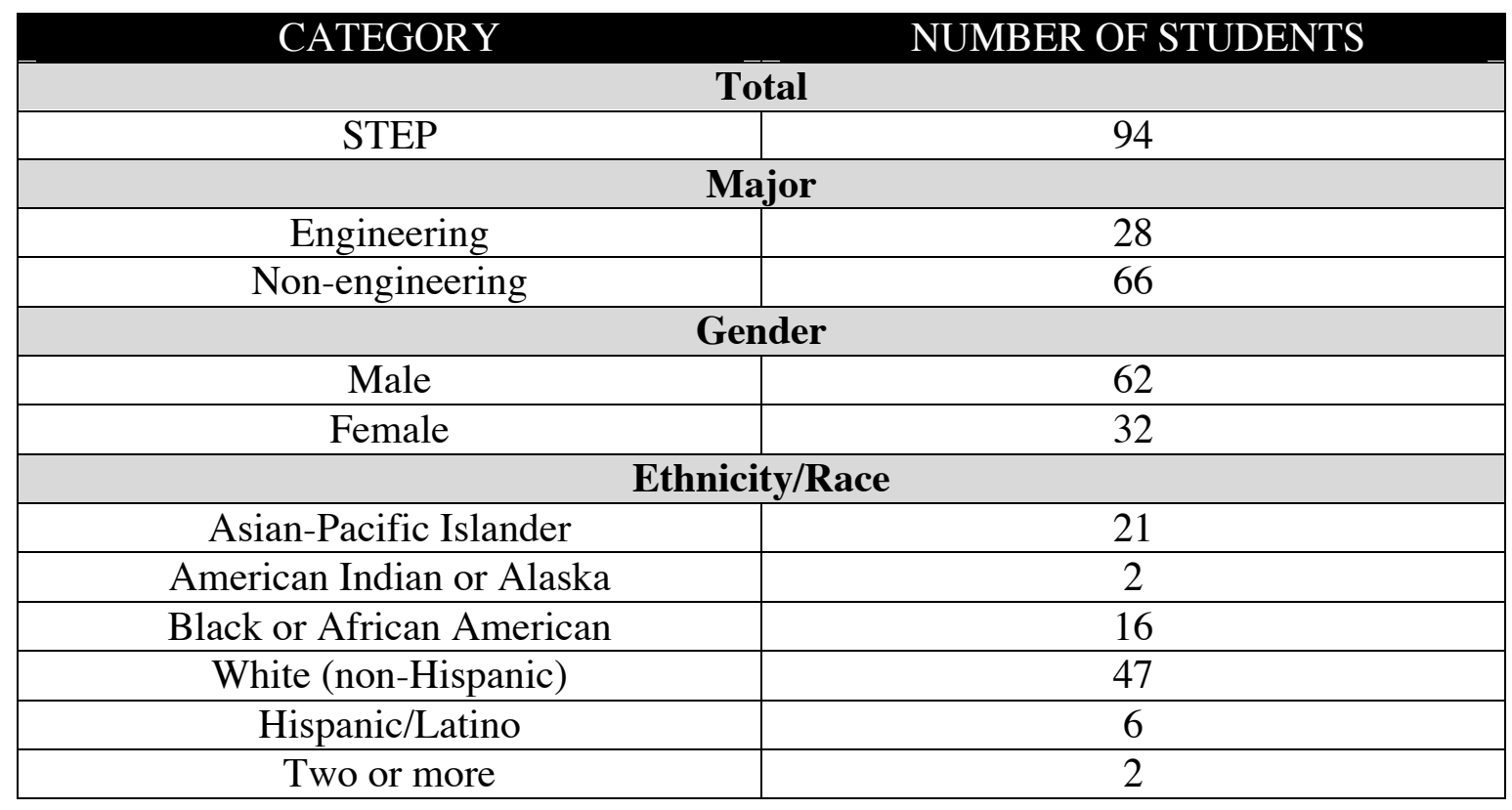


A qualitative multicase study ${ }^{[4,5]}$ was completed to understand the experience and academic motivation of each individual at the conclusion of the program. By examining, in detail, six different student-experiences, it was possible to look for common themes that emerged across the participants. At the same time, this approach allowed us to gain a better understanding of whether there were unique experiences that each student had and, if so, to capture sufficient detail about these experiences. A qualitative methodology using multiple cases in this manner allowed us to gather information about STEP that can lead to a better understanding of how to design the program to help students as they transition. This method provides rich detail and different information than obtained from an evaluation survey, which might capture students' responses about the program but would not provide sufficient detail to help better understand how STEP impacts individual students differently.

\section{Data Collection}

Qualitative (and some quantitative) data were collected from six students using pre-surveys and individual interviews; their academic performance during STEP was also reviewed. The research team developed the data collection instruments to focus on the stated program goals and the constructs outlined in the MUSIC Model of Academic Motivation.

Data were collected before STEP using a pre-survey to determine why each student chose to participate in the program. The survey instrument also included basic demographic information (i.e., major, sex, and race/ethnicity). At the end of the survey, students were asked to self-identify if they were interested in participating in a one-on-one interview at the conclusion of STEP. Survey participants that indicated interest in being interviewed were then screened so the authors could select students that provided variation regarding gender, race, and major. The author not directly involved in directing STEP then scheduled and conducted interviews with six students during the last week of the program, prior to them receiving their final grades. Participant demographics and pseudonyms, used to conceal the identity of the participants, are presented in Table 2.

Table 2: Participant Demographics

\begin{tabular}{|c|l|l|l|}
\hline \multicolumn{2}{|c|}{ MAME } & \multicolumn{1}{c|}{ MAJOR } & \multicolumn{1}{c|}{ RACE/ETHNICITY } \\
\hline Ashley & Engineering & Female & Black or African American \\
\hline Brittany & Non-engineering & Female & Black or African American \\
\hline Charles & Engineering & Male & White (non-Hispanic) \\
\hline Daisy & Non-engineering & Female & White (non-Hispanic) \\
\hline Ella & Non-engineering & Female & Asian-Pacific Islander \\
\hline Frank & Non-engineering & Male & Asian-Pacific Islander \\
\hline
\end{tabular}

The semi-structured interviews were the primary data source for the qualitative approach. An interview protocol was used to guide the discussion and focused on the program goals, academic motivation, and overall experience of each student. During the interview, each student was asked questions about his or her experience during STEP such as "How would you describe your experience during STEP this summer?" and "In what ways do you believe participating in STEP will impact your experience as a student in the future?" Students were also asked questions directly related to the MUSIC Model such as "How has STEP influenced how in control you feel 
over your engineering experience?" and "How has STEP influenced your confidence in your ability to be successful as an engineering student?" Lastly, students were asked questions related to the stated STEP goals such as "Did participating in STEP help you become familiar with the university community? If so, how?" Each interview lasted approximately 45-60 minutes and was audio recorded and transcribed verbatim.

\section{Data Analysis}

Interview data were analyzed using a priori codes ${ }^{[10]}$ from the MUSIC Model, open coding techniques ${ }^{[11]}$, and narrative analysis ${ }^{[12]}$. First, each member of the research team coded the interviews independently using a word processor such that highlighting and inserted comments denoted a code. An example of a priori coding is the statement, "It made me, definitely think that I can make it but I have to work really hard" being coded as "Success" after a participant responded to a question regarding the influence STEP had on her confidence in her ability to be successful as an engineering student. An example of open coding is the statement, "It kind of made me reevaluate like who, what type of people I need to hang out with so that we're actually working instead of just talking" being coded as "Self-management" as a participant describes her overall STEP experience.

Next, the researchers discussed each student's data to reach intercoder agreement on the coded sections and salient themes for each participant ${ }^{[11]}$. Narrative analysis, which entails synthesizing data into a coherent whole ${ }^{[12]}$, was then used to turn the themes into a story about participating in a summer bridge program for each participant. Narratives analysis was used to construct a story that represents each student's views on their preparation for engineering and reasons for majoring in engineering, lessons/skills taken away from the program, and academic motivation towards engineering. Lastly, the authors reviewed each story to ensure the essence of each experience was captured.

\section{Results}

In the following section, the narrative for each participant is presented in a parallel fashion to facilitate comparisons: each story begins with the student's reasons for participating in STEP and perceived preparation for engineering; next, the student's experience and the lessons he or she learned are presented; lastly, the student's academic motivation towards engineering at the conclusion of the program is highlighted. Regarding academic motivation, the common themes that emerged through the narrative analyses were that participating in STEP helped students realize that their success is connected to how hard they work (i.e., empowerment/success) and that the college of engineering is willing to help them if they help themselves (i.e., caring). Usefulness and interest were not influenced in a similar fashion. There were also unique benefits such as gaining self-awareness, improving self-management and time-management skills, forming relationships with peers and faculty, etc. 
Participant 1 - Ashley

Ashley, an African-American, was admitted directly into engineering. She participated in STEP to "practice" before the fall and prepare for classes. Ashley did not feel very prepared for engineering, though she completed programming, science, and math courses in high school. During STEP, completing Chemistry helped Ashley clarify what she did not know and completing Math presented a challenge as she had only taken pre-calculus and the STEP course covered topics such as linear algebra, vector geometry, and calculus - she thought her math preparation was inadequate. While Ashley's reason for selecting engineering and her major interest (i.e., computer science) did not change, STEP did help solidify her plans. Initially, she wanted to transform the "media industry" and computer science into something cool; she left STEP with a plan. Instead of saying, "I want to do these two things," she could say, "I need to go to this department so I can do these things."

Ashley also developed self-awareness: STEP made her re-think how to study, how much time was needed, and how to organize time so it worked for her. STEP also helped Ashley discover her study preferences. She states, "I definitely need to go back and look at the notes and read the textbook and try practice problems and things like that." Ashley also gained social awareness. She states, "Socializing is kind of a hard thing to do because I'm kind of introverted. But STEP helped me realize how college might start out.... it helped me realize these are the type of people I want to be around... these are the type of people I can study with.... and they may be two different sets of people, but that's ok."

Ashley also learned lessons regarding self-management and believed this was the result of balancing "extracurricular stuff" and studying. With regards to her academics, she stated, "I didn't do to well on that [exam] and it's because I was doing something else instead of studying." Her response was, "I need to study more, so I need to figure out what I can do and what I can't do in this amount of time." Ashley also noticed the change in pace and the need to "actively seek" teachers during office hours. She planned on studying more, forming a study group for each class, seeking tutors if she struggles in a course, and planning extracurricular activities around her study schedule in the fall.

Ashley's academic motivation was also impacted by STEP. With regards to usefulness, she believed engineering courses would help her "think outside of the box," which was important since engineers are "inventing things" and being innovative. The engineering course helped her realize that she could not just "regurgitate" things that she learned: she would have to apply them. With regards to empowerment and success, she stated, "It made me definitely think that I can make it but I have to work really hard." Ashley began thinking about whether she wanted to graduate in four or five years and if she would take classes or intern over the summer. STEP also helped her realize that "you don't particularly have to be intelligent or less intelligent to understand concepts. You're just going to have to try harder." With regards to interest and enjoying engineering, she believed she would better enjoy engineering since she now had "experience in these classes" and would be more comfortable since she "understand[s] the amount of work" required. With regards to caring, STEP convinced Ashley that the college cares about her academically and personally. Specifically, the center director led her to believe that "If you're willing to help yourself, she's willing to help us." For her, this was "definitely a motivator to succeed as much as I possibly can." 


\section{Participant 2 - Brittany}

Brittany, an African-American, was not admitted into engineering and participated in STEP to prepare for college and possibly transfer into engineering. Brittany did not feel prepared for engineering and had one class during high school that "semi" prepared her: she learned valuable lessons in microbiology such as the "foundation of how to study and how to be on time and turn assignments in on time." She also had experience with classes related to civil engineering, digital electronics, and engineering design. Regarding STEP, she did not know what she was getting herself into and stated, "I figured it would be like college classes and I would learn how to study and things like that." She thought STEP was an interesting experience, and she stated, "I've learned a lot actually. And I learned what I don't like. And I've learned how to study, sort of, kind of. And prioritize my time more"

Through STEP, Brittany realized that she did not want to be an engineer. When asked if STEP influenced her decision, she stated, "No, I was pretty much decided. But... I wanted to give it a try because my mom wanted me to and I figured that if I learned something here, I would get something out of this program." STEP made her realize just how much she did not like science and math. Though she did not want to give up on engineering for a reason such as it being "too hard," she realized that she would not be happy and figured that her happiness and pride were more important. She knew there were people in her life that wanted her to be an engineer but she believed they would "survive" either way.

Brittany also learned about college in general. She believed STEP better prepared her for college, particularly since she "never had to actually work hard... actually reading textbooks and applying them and learning for myself instead of the teacher actually giving me the information and I had to just regurgitate it." Brittany felt that she had an "enriching" experience and would benefit from knowing "how college works and what they expect of you." She also realized how much of a "strain" college can be and stated, "Basically you have your own self to rely on here. Even though you have other people and friends... no one knows you but yourself, really. And so, you have to be confident and be able to work through your problems, try to get homework done and things like that." Overall, Brittany enjoyed the freedom that came with being a college student and liked figuring out how the classes worked, where she needed to be by a certain time, and how to get organized.

Brittany also began thinking about the future through the STEP. In particular, she stated, "I just felt like it was preparing us for something that we don't really know about just yet" and thought it was kind of scary that she was "thinking about a job" even though she just started college. She realized that as a college student she would need to "look forward and be progressive" and felt like she benefited from being introduced to "resume skills and how you should prepare it and how you should present yourself."

Brittany's academic motivation was impacted by STEP. While she did not plan on majoring in engineering, she still believed engineering was useful, though something she personally was not interested in. She also felt like the college of engineering cared about her and stated, "I feel like they really care actually. Everyone was like really nice and receptive and willing to talk to you and help you out and things." 


\section{Participant 3 - Charles}

Charles, a white student, was admitted into engineering and participated in STEP for the advantages he could get to "enter into a successful career path." He did not feel prepared for engineering, as he had not taken anything "even remotely related" to engineering before STEP. Regarding STEP, Charles did not "expect it to be this difficult academically," though he admits that he did not use it "solely, or mostly, for an academic purpose." He stated, "I kind of wanted to do this so I could meet people; get kind of accustomed to the school; learn the ins and outs." Furthermore, STEP solidified his major selection: while Charles chose the field because his grandfather was an engineer, he stated, "I feel like I'm more comfortable with [becoming an engineer] than I may have been before. I thought, 'All right math, physics - that doesn't always equal engineering. Maybe that equals a physicist or something like that." STEP helped him realize that his interests did in fact equal engineering.

Charles also realized that he needed an improved work ethic - he described himself as "very lazy" and knew it was something that he needed to overcome. During STEP, Charles realized that some assignments could take more time than he was willing to commit. He stated, "I could do [the work]... I just don't love wasting that kind of time. Even though it's not wasting because it's learning and stuff." While Charles did not perform well academically during STEP, he was challenged. Regarding the impact STEP had on his academic enrichment, he stated, "I feel like the material that they taught was not just going over high school stuff. It was going more in depth and more difficult material, which will be useful throughout my time at Virginia Tech."

Charles also "got the experience of college... before it actually started" and was able to learn some of the ins and outs of Virginia Tech. For example, during a faculty lunch, Charles talked with a professor about "everything in the school. Like what to avoid... study habits and stuff like that." After participating in STEP, Charles "won't just be like one freshman. [He'll] be able to explore the other realms of the upperclassman possibly." Charles believes STEP gave him an edge, both academic and socially, since he already knows a "bunch of people," "what's going on," and "some of the key spots."

Charles' academic motivation was also impacted by STEP. With regards to usefulness, STEP taught him that he would "need to learn how to apply what you know to be a good engineer." Charles believed engineering courses would be necessary for him to become a very successful engineer. He believe that, through the courses, he would get to know "all those little bits and pieces that really make up what an engineer needs to be." With regards to empowerment and success, Charles was impacted both negatively and positively. In particular, he believed that the classes would be tough but he could succeed if he would "put [his] all in and try [his] best." He initially thought engineering would be easy since he took engineering classes in high school, but discovered it to be much different. He stated, "I feel very scared, because [engineering] seems very daunting." However, he did believe engineering would be "much easier than it was, because [he'll] know what to expect [after STEP]." Charles also felt like the college of engineering cared about him and stated, citing actions from the center director, "I feel like definitely if I have any problems, they will be there to help me. But I have to put in effort as well. I can't just let them do it for me. I have to do at least some of it." 
Participant 4 - Daisy

Daisy, a white student, was not admitted into engineering and participated in STEP to "attempt to get into the College of Engineering and to meet people before fall semester." She felt like high school somewhat prepared her for engineering and did not "think STEP was going to be as difficult as it is." Overall, Daisy had a "good experience, not only for the workload, getting use to that, but meeting new people, getting use to the campus, and also making contacts." Though Daisy was unsuccessful in her attempt to transfer into engineering, she still wanted to be an engineer at the end of the program.

Daisy also formed relationships during STEP and believed "participating in STEP will be beneficial to [her] through the people [she] met." Daisy believed the best part of STEP was a teambuilding activity where she formed a group of friends that she planned on "holding through the next four years." She was also able to interact with the STEP director, who served as her advisor during the program; she found this useful because it allowed her to get to know him and get feedback on various topics.

Daisy also realized the importance of a strong work ethic and balancing the workload. Regarding STEP, she stated, "It gets [you] use to, I suppose, the workload difference between high school and college. I don't think I expected to have so much in a short period of time and I figured it would be a little bit easier considering you are paying to be here, but that's also how regular college is too." Through this experience, Daisy was able to increase her drive and gain "different ideas on how to go about studying."

Lastly, Daisy received a lot of information. For example, she started STEP thinking she would major in aerospace engineering; after getting more information on her options, she began thinking industrial \& systems engineering would be a better fit. She also got information on how many hours to study for each credit hour, "different studying techniques as far as reading the book and taking your own notes," and preparing for the career fair.

Daisy's academic motivation was also impacted by STEP. With regards to usefulness and interest, she anticipated engineering being "enjoyable and valuable" and did not believe STEP impacted how she felt in this area, though she did find the program itself both valuable and enjoyable. With regards to empowerment and success, Daisy stated, "I'm in control of my own career path as far as engineering goes, because it depends on how well I do; how much work I put forth, even in STEP, to get into engineering." While she did not enter the program with this mindset, she was able to leave with an improved outlook. She stated, "Beforehand, whenever I didn't understand something, I would just assume it's cause I'm stupid. I'm not intelligent enough to be able to understand a certain topic and do well on being tested on the topic. But for STEP, it's like... basically they have a plan that says you are responsible for your grades. It's how much work you put forth into getting your grades." With regards to caring, she stated, "I hadn't previously anticipated like getting to know professors, and even [the center director], on a personal level. But I realize now that it's a lot easier to get to know the people that are trying to influence you in engineering." 


\section{Participant 5 - Ella}

Ella, an Asian-Pacific Islander, was not admitted into engineering and participated to "get into the College of Engineering." During high school, she took an introduction to engineering and principles of engineering course and felt somewhat prepared to major in engineering. Regarding her high school preparation she stated, "For the engineering stuff, it did help me. But for the random math, not really." In her opinion, the high school engineering courses were "more practical" and STEP was a "more problem solving type of thing." Since Ella did not consider engineering as a major until after her junior year, she was also unable to take calculus: she took pre-calculus her senior year. Before STEP, Ella "expected it to be less hard, but apparently it was really hard." She also expected to meet a lot of people, work hard, and not have much fun. Overall, Ella had fun during STEP and learned several lessons. Though Ella was unsuccessful in her attempt to transfer into engineering, she still wanted to be an engineer at the end of STEP and was considering majors she had not previously. She initially wanted to major in computer science but she left the program looking for something that she "really, really want[s] to do."

For Ella, STEP was really about making the transition from high school to college, particularly getting use to (1) being away from her parents, (2) the college workload, and (3) forming a social network. Regarding the transition, Ella stated, "You get to meet a lot of people and make connections and learn something about yourself that you never knew before. Mainly because you didn't have your parents around to like tell you to do stuff... or yelling at you for getting a C." She believed STEP is a "really wonderful way to kind of open up your world and see things the way you've never seen it before." Regarding the workload, she stated, STEP "kind of pushed you to the limit, for you to work harder than you did in high school. And then I think, in that way they got me to work really, really hard and to learn a lot more than usual." She also benefited from the tight deadlines, which helped her get "into the habit of doing stuff the day when it was assigned." Though it was hard, Ella had fun and met "tons of people and made friends prior to coming to Virginia Tech in the fall."

Ella's academic motivation was also impacted by STEP, specifically regarding empowerment. With regards to empowerment, she did not feel like she had "absolute control" over her experience since she would have to rely on the performance of her peers in certain instances. After being told by a high school teacher that "the key to success in college is to do better than the person next to you, cause in the end they're going to curve and stuff," she felt like being surrounded by other smart people in engineering took away some of her control over her experience: she believed she has to outperform her peers and realized that this may be difficult and beyond her control. However, she did feel like her improved "time management and the work ethic and all that kind of stuff" will help her gain some control over her experience. With regards to success and interest, she was confident that she would enjoy and do well in engineering as a result of the friends she made. Ella believed the friends she made would make the experience more enjoyable and that since they were "really smart" they could help her in her courses. Regarding usefulness, she believed engineering would help her get a job. Lastly, regarding caring, she stated, "I really do believe that they cared about the students, both personally and academically. And I honestly did not expect that. I expected college of engineering to be full of cold, smart people and I guess it's not." 
Participant 6 - Franklin

Franklin, an Asian-Pacific Islander, was not admitted into engineering and participated in STEP to "start [his] freshman year as an engineering major." He felt prepared for engineering as he had already seen "calculus and chemistry and physics" during high school. Overall, Franklin felt like STEP simulated college (they were "pretty much treated like college students"), though he did expect the problem to be less "difficult" and "hectic." At the conclusion of STEP, Franklin was admitted into engineering and while STEP did not change his reason for wanting to be an engineer it "definitely confirmed that engineering is the major for [him] at the moment."

For Franklin, STEP provided a simulation of college and academic enrichment. Regarding his academic experience, he stated, "I feel like I've learned a lot academically. Pretty much every subject, I didn't know things that were taught. So I think it did enrich, and I was exposed to things that I would see in the upcoming school year." Through this simulation of college, Franklin was also able to learn "time management skills" and "just how the college experience would go." At the conclusion of the program, he credited his improved time management skills to the busy schedule and stated, "It takes up more time, but it teaches you how to manage the time that you have;" this lesson was also reiterated by the center director who "really got the point across that needed to be made as far as time management or doing certain things." Franklin also felt like getting to "meet people in a smaller environment before it gets huge" would be helpful during the fall and would already know his way around campus. The simulation also provided Franklin with a chance to evaluate his own performance as a student. He stated, "I think I'm getting more of a feel for it. I don't think I'm as efficient and good about studying that I should be. I know I'm putting the time in, but I don't know if I'm putting the time in correctly. So, I feel like I'm going to improve in that and I have already improved with my study skills." Ultimately, Franklin "basically made the transition to a college student [during STEP], when it [didn't] exactly count as far as grades wise." After getting this simulation he stated, "I have experience and now I hopefully don't trip up when it counts."

Franklin's academic motivation was also impacted by STEP. With regards to empowerment, STEP showed him that "You sort of determine your own destiny with how hard you work and things of that nature." While he assumed college would be this way before the program, participating in STEP helped confirm his assumptions. Regarding usefulness, Franklin did believe the courses would "be useful going forward" and that a lot of the material he saw during STEP would be revisited once the semester starts. STEP also influenced Franklin's expectations for success, both if he could be a successful engineer and whether or not he wanted to be one. He stated, "I think I had doubt, not only if I could be a successful engineer but whether I wanted to do engineering. And I think STEP has helped me. It has directed me towards that and showed me that I can be successful in engineering and that I do want to be an engineer." His interest was also impacted and he believed that through being an engineer you could be with "people who are similar to you... have similar strengths and weaknesses, so you can get along with that crowd better" and felt like this made it enjoyable; he also saw value in the degree as it would impact his "ability to get a job after college." Lastly, his caring was impacted through the accommodations the STEP staff made for him and the entire cohort, giving them "as many opportunities as we could possibly need in order to become engineers." 


\section{Discussion}

Based on the narrative analysis, we were able to identify the impact that participating in a summer bridge program can have on academic motivation and the lessons students learn as they transition towards engineering. We set out to understand how diverse students with varying backgrounds experience the same summer bridge program in order to improve our understanding of how students are impacted by these interventions.

First, we found that students have different reasons for participating in summer bridge programs, which may impact how they expect to and actually benefit from participating. For example, Charles participated in STEP for advantages he could get to enter into a successful career path, while Ashley participated to practice before the fall and prepare for classes. At the conclusion of the program, Charles realized his work ethic needed improving and learned the ins and outs of the university, while Ashley gained self-awareness and self-management skills directly related to being a productive student. This finding suggests that practitioners should talk to students about their reasons for participating in a summer bridge program and the opportunity for benefits that may be overlooked at the beginning of a program. That is to say, if a director is aware that a student such as Charles is not initially interested in the academic preparation afforded by the program, he or she can discuss this aspect of the program in advance so Charles is aware of this potential benefit as well. On the contrary, the director can also ensure that students such as Ashley take advantage of the non-academic benefits afforded by the program. This finding also suggests that while summer bridge programs may be designed to provide students with a similar experience, students will decide to participate for various reasons and will thus benefit from participating differently.

We also found that that participating in a summer bridge program can help students realize that how hard they work will directly impact how successful they are as an engineering student. Since students often expect their high school work ethic to result in similar success during college, participating in a summer bridge program provides students with the opportunity to figure out how much work is required to be successful while in an environment that can reiterate that if they are not successful it is because they are not working hard enough, not because they are not smart enough. For example, Daisy mentioned how before STEP she would attribute her failure to not being intelligent enough to understand a topic but, through participating in STEP, she recognized that how much work she put forth was responsible for her grades. Ashley and Charles also mentioned that the effort they put forth would determine how successful they were.

Lastly, we found that participating in a summer bridge program can demonstrate that the college of engineering cares about students. Through their interactions with the faculty/staff in charge of STEP, each student believed that the college cared about them and would be willing to assist them if necessary. For example, Ella did not expect the college to care when she started the program but was convinced that they did once the program ended; this sentiment was expressed by each of the students.

\section{Conclusion}

In conclusion, our research demonstrates that participating in a five-week summer bridge program can impact a student's academic motivation and revealed lessons pertinent to individual 
students that can be gained. In particular, participating in STEP helped students with the following:

- Gaining self-awareness;

- Improving self-management and time-management skills;

- Confirming the decision to major (or not major) in engineering;

- Learning lessons about being an engineering student and college life in general;

- Thinking about the future, both academically and professionally;

- Forming relationships with both peers and faculty;

- Reevaluate work ethic and adjusting to the increased workload; and

- Transitioning from being a high school student to a college freshman.

With regards to academic motivation, participating in a summer bridge program can help a student realize that his or her success is influenced by how hard they work (empowerment and success) and that the college of engineering is willing to help them if they help themselves (caring). While participating in a summer bridge program may also help students solidify their choice to major in engineering, the impact on how useful they consider engineering courses and the level of interest they have regarding the major does not appear to be as heavily influenced by participation.

\section{References}

1. M. W. Ohland and E. R. Crockett, Creating a catalog and meta-analysis of freshman programs for engineering students: Part 1: Summer bridge programs, American Society for Engineering Education Annual Conference and Exposition, June 16-19, 2002.

2. J. Gleason, K. Boykin, P. Johnson, L. Bowen, K. Whitaker, C. Micu, D. Raju and C. Slappy, Integrated engineering math-based summer bridge program for student retention, Advances in Engineering Education, 2(2), 2010, pp. 1-17.

3. T. E. Murphy, M. Gaughan, R. Hume and S. G. Moore Jr, College graduation rates for minority students in a selective technical university: Will participation in a summer bridge program contribute to success?, Educational Evaluation and Policy Analysis, 32(1), 2010, pp. 70-83.

4. R. K. Yin, Case study research: Design and methods, 4, 4, Sage, 2009.

5. $\quad$ R. E. Stake, Multiple case study analysis The Guilford Press New York, 2006.

6. B. D. Jones, Motivating students to engage in learning: The MUSIC Model of Academic Motivation, International Journal of Teaching and Learning in Higher Education, 21(2), 2009, pp. 272-285.

7. B. D. Jones. The MUSIC model of academic motivation 2010 [cited 2011 May 7th]; Available from: http://www.ep.soe.vt.edu/ms/.

8. B. D. Jones, An examination of motivation model components in face-to-face and online instruction, Electronic Journal of Research in Educational Psychology, 8(3), 2010, pp. 915-944.

9. W. C. Lee, R. L. Kajfez and H. M. Matusovich, Motivating engineering students: Evaluating an engineering student support center with the MUSIC model of academic motivation, Journal of Women and Minorities in Science and Engineering, 19(3), 2013, pp. 245-271.

10. M. Q. Patton, Qualitative research and evaluation methods Sage Publications, Inc, 2002.

11. J. W. Creswell, Research design: Qualitative, quantitative, and mixed methods approaches 3, 3, Sage Publications, Inc, Thousand Oaks, California 2009.

12. D. E. Polkinghorne, Narrative configuration in qualitative analysis, International journal of qualitative studies in education, 8(1), 1995, pp. 5-23. 